\title{
Preface: 7th Intemational Conference on Plasma Medicine (ICPM-7) (Part I)
}

The 7th International Conference on Plasma Medicine was hosted by Drexel University's C. \& J. Nyheim Plasma Institute on Drexel's campus in Philadelphia, Pennsylvania, USA, from June 17-22, 2018. This conference covered a range of topics in applications of non-equilibrium discharges in biology, bioengineering, and medicine:

1. Fundamentals of atmospheric plasmas

2. Plasma sources for biomedical applications

3. Plasma liquid interactions, plasma activated liquids

4. Plasma-cell and plasma-tissue interactions, including biological and biochemical reactions

5. Plasma-surface interactions/modifications for biomedical applications

6. Plasma-based decontamination and sterilization

7. Plasma for pharmaceutical applications, and biochemical and biomolecular engineering

8. Plasma medical applications in clinical and animal studies

9. Plasma agricultural applications

10. Plasma modeling and numerical simulation

The conference attendees enjoyed a 5-day scientific program with 5 early morning plenary talks, 23 invited talks, 87 regular oral presentations, and 149 posters presented by 89 students and 175 faculty and industry professionals.

The conference was attended by 287 participants from 27 countries (Fig. 1).

More information about ICPM-7 is available on our conference website at http:// icpm7.plasmainstitute.org.

The 8th ICPM is tentatively scheduled for June 14-19, 2020, in Songdo Convensia, Incheon, Korea, hosted by Prof. Eun Ha Choi and his team from Kwangwoon University. More information about ICPM-8 will be made available on the conference website at http://icpm8.or.kr (link is not yet active at time of submission of this article). ICPM-8 will be hosted with the 10th International Symposium on Plasma Bioscience (ISPB 2020) and the 3rd Summer School on Plasma Medicine (June 12-13, 2020).

\section{Guest Editor}

Alexander Fridman

C. \& J. Nyheim Plasma Institute, Drexel University

Camden, NJ, USA 


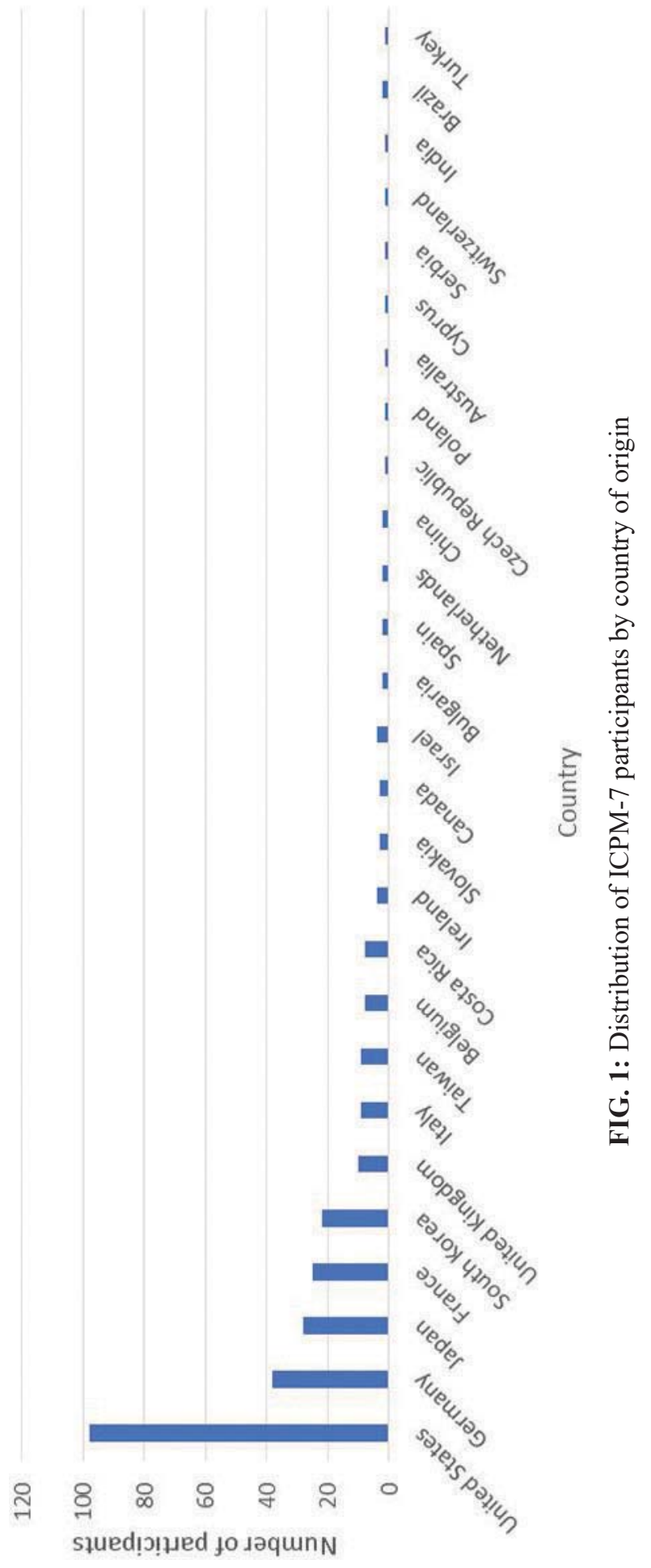

